\title{
Efeitos da suplementação de ácidos graxos poli-insaturados na fibrose cística: uma revisão de literatura
}

\author{
Acid supplementation effect of polyunsaturated fatty in cystic fibrosis: \\ a literature review
}

Daiane Jácome Leite ${ }^{1 *}$, Camila Kellen de Souza Cardoso ${ }^{2}$

${ }^{1}$ Nutricionista. PUC - GO; ${ }^{2}$ Nutricionista. Mestre em Nutrição em Saúde FANUT - UFG, Doutoranda em Ciências da Saúde. UFG, Docente. PUC-GO

\begin{abstract}
Resumo
Introdução: a fibrose cística (FC) é uma doença autossômica recessiva caracterizada, especialmente, pela alta produção de muco, em razão de uma alteração na proteína regulador transmembrana da FC (RTFC). Dentre as comorbidades secundárias, a alteração no metabolismo lipídeo é impactante e muito discutida e vem-se estudando a interferência dessa alteração nos processos inflamatórios que ocorrem frequentemente em pacientes fibrocísticos. Objetivo: Avaliar os possíveis efeitos da suplementação de ácidos graxos poli-insaturados (PUFAs) na fibrose cística, notadamente do ponto de vista inflamatório. Metodologia: revisão de literatura, com busca sistemática nas bases de dados Pubmed, Science Direct, Bireme e Periódicos CAPES. Resultados: a suplementação de PUFAs aumenta os níveis séricos de ácido linoleico e decosahexaenoico e reduz os níveis séricos do ácido araquidônico (AA) e do ácido Mead. Conclusão: já foram realizados ensaios clínicos com pequeno número de indivíduos e em curto período de tempo, porém, ainda não existe um consenso para o protocolo de suplementação de PUFAs. Nos estudos observados, encontraram-se resultados positivos, sugerindo que essa suplementação pode ser um aliado no manejo da doença, embora sejam necessários mais estudos para melhor esclarecer o mecanismo desse efeito benéfico, bem como para estabelecer a melhor dose para suplementação de PUFAs na FC. Palavras-chave: Fibrose Cística. Suplementação. Ácidos Graxos Insaturados. Ácido Linolênico. Ácido Linoleico.
\end{abstract}

\begin{abstract}
Introduction: cystic fibrosis (CF) is an autosomal recessive disease characterized especially by the high production of mucus due to a change in transmembrane regulator protein FC (CFTR). Among the secondary comorbidities, changes in lipid metabolism is striking and much discussed. Currently studying the hypothesis of how this change affects the inflammatory processes that often occurs in this patient. Objective: To evaluate the possible effects of supplementation of polyunsaturated fatty acids (PUFAs) in cystic fibrosis, primarily the inflammatory point of view. Methodology: it is a literature review, with systematic search in the databases: PubMed, Science Direct, Bireme and CAPES journals. Results: PUFA supplementation increased the serum levels of linoleic acid and decosahexaenóico also reduced the serum levels of arachidonic acid and Mead acid. Conclusion: clinical trials are already done with a small number of people and carried out in a short period of time, and there is no consensus in the supplementation protocol. Observed in studies we met positive results, suggesting that supplementation of PUFAs can be an ally in the management of the disease, however, more studies are needed to clarify the mechanism of this beneficial effect and the best dose for PUFA supplementation in FC.

Keywords: Cystic fibrosis. Supplementation. Unsaturated fatty acids. Linolenic acid. Linoleic acid.
\end{abstract}

\section{INTRODUÇÃO}

A fibrose cística (FC) ou mucoviscidose é uma doença hereditária autossômica recessiva causada por diversas mutações no gene que codifica o regulador transmembrana da fibrose cística (RTFC), especificamente no cromossomo 7. A proteína RTFC, em condições fisiológicas adequadas, regula o canal iônico, principalmente de cloreto de sódio ${ }^{1,2,3}$. A disfunção desse canal causa um desequilíbrio no transporte de cloro, sódio e água que propicia a desidratação da superfície celular, favorecendo a formação de um muco espesso ${ }^{1,2,3}$. Consequentemente, os principais sintomas clínicos da FC são a perda de sal

Correspondente/Correponding: * Daiane Jácome Leite - End: Rua 10 esq. com a 3 no 298 Edifício Atlânta Setor Oeste - Tel: (62) 8212-2892 -E-mail: daileitenutri@gmail.com por meio do suor e a formação desse muco que ocasiona o aparecimento de doenças secundárias ${ }^{1,2,3}$.

As principais comorbidades da FC são insuficiência pancreática (IP) com obstrução de ductos do pâncreas, dos canais biliares, do intestino e dos brônquios, bem como doença pulmonar supurativa crônica, infecções pulmonares de repetição e inflamação crônica ${ }^{4}$. Observa-se, também, a infertilidade em indivíduos do sexo masculino, assim como a má absorção de nutrientes, incluindo alterações no metabolismo lipídico ${ }^{4}$.

Frequentemente, pacientes fibrocísticos apresentam reduzidos níveis séricos de ácidos graxos essenciais (AGE), especialmente do ácido linoleico (AL) e do ácido docosahexaenoico (DHA), deficiência que pode ser encontrada também nas membranas plasmáticas e em amostras histológicas ${ }^{5,6}$. A normalização ou a modificação do perfil 
de AGEs poderia reduzir a inflamação crônica, a perda ponderal e a desnutrição que complicam o prognóstico desse grupo de pacientes ${ }^{6}$.

Diversos estudos vêm avaliando o efeito da suplementação de ácidos graxos poli-insaturados e investigando se as alterações do metabolismo de AG podem ser corrigidas e se, mediante essa normalização, pode ocorrer a melhora do quadro inflamatório crônico característico dos pacientes fibrocísticos, com consequente melhora do seu estado

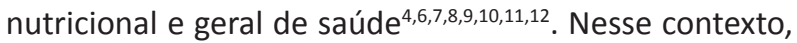
o objetivo do presente estudo foi investigar, na literatura científica, os possíveis efeitos da suplementação de ácidos graxos poli-insaturados na fibrose cística, especialmente do ponto de vista da inflamação.

\section{METODOLOGIA}

Essa revisão de literatura com busca sistemática, realizada no período de agosto de 2014 a maio de 2015, considerou as publicações de 2010 a 2015. Procedeu-se a essa busca nas bases de dados Pubmed, Science Direct, Bireme e Periódicos CAPES, com a utilização dos termos:
"Cystic fibosis", "Fibrose Cística”, "ômega 3", "omega 3", "suplementação", "supplementation", "docosahexaenoic acid”, "DHA", "eicosapentaenoic acid”, "EPA", "PUFA", "ácidos graxos", "fatty acid", "metabolism" e "lipid".

Adotaram-se os seguintes critérios de inclusão: artigos de revisão sistemática ou metanálise, ensaios clínicos que utilizaram suplementação de ômega 3 e/ou ômega 6 , modelo in vitro, modelo animal e pesquisas realizadas com humanos de todas as faixas etárias e ambos os sexos. Em contrapartida, foram excluídos artigos anteriores ao ano de 2010, incluindo-se, porém, $20 \%$ de publicações relevantes anteriores a essa data. Foram utilizados também livros específicos em bioquímica.

A busca e a interpretação dos artigos foram realizadas da seguinte forma: caso o título do artigo referisse o assunto do presente estudo, realizou-se a leitura do resumo; constatando-se que tratasse de assunto relevante para a presente pesquisa e se adequasse aos critérios de inclusão e exclusão propostos, deu-se procedimento à leitura e à avaliação dos artigos por completo.

Figura 1 - Fluxograma de busca e seleção dos documentos utilizados

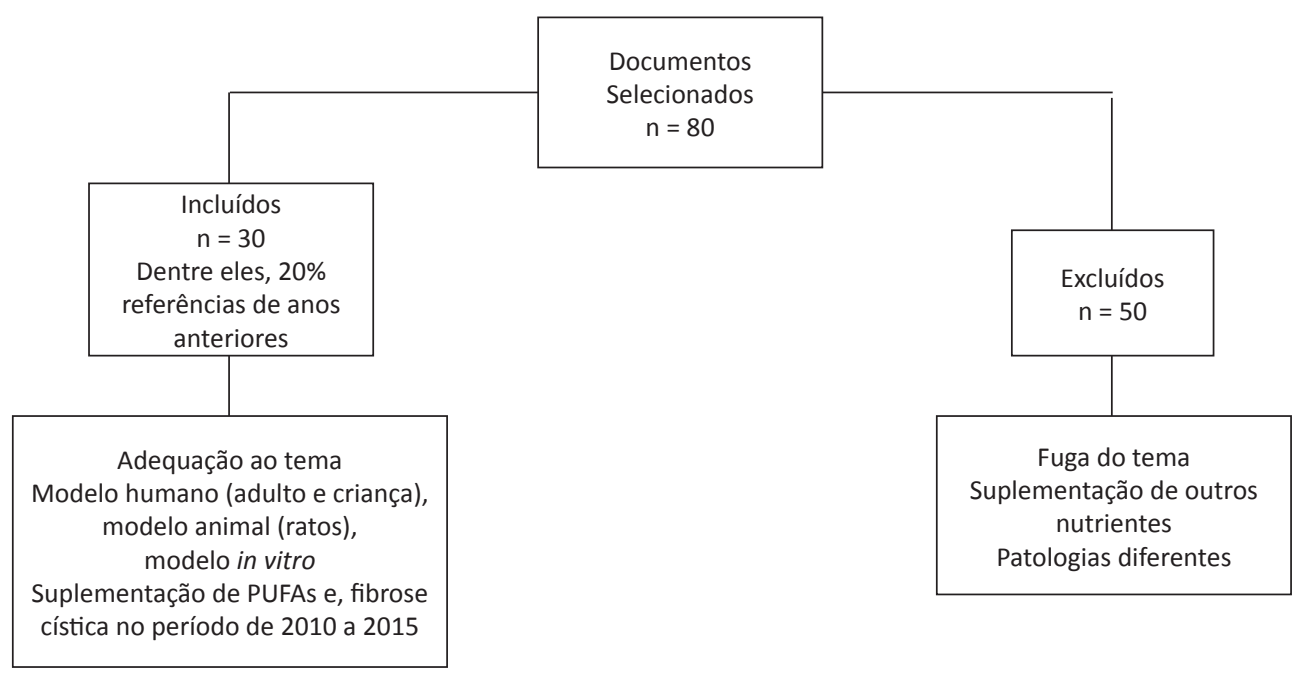

Fonte: Elaboração das autoras. 
RESULTADOS

Tabela 1 - Resultados dos efeitos da suplementação de ácidos graxos poli-insaturados na fibrose cística

\begin{tabular}{|c|c|c|c|c|}
\hline Autor & Estudo & Amostra & Protocolo & Efeitos \\
\hline Biervliet et al. (2008) & $\begin{array}{l}\text { Modelo humano } \\
\text { Ensaio clínico, } \\
\text { controlado por } \\
\text { placebo, duplo- } \\
\text {-cego }\end{array}$ & $\begin{array}{l}17 \text { pacientes com FC } \\
>6 \text { anos de idade } \\
\text { Intervenção: } 1 \text { ano }\end{array}$ & $\begin{array}{l}\text { Grupo intervenção: óleo rico em DHA } \\
\text { de algas } \\
\text { Grupo controle: óleo de semente de } \\
\text { girassol }\end{array}$ & $\begin{array}{l}\text { DHA alterou os níveis séricos de } \\
\text { fosfolipídios para um perfil menos } \\
\text { pró-inflamatório } \\
\text { Nenhuma melhora clínica conclusi- } \\
\text { va foi observada }\end{array}$ \\
\hline Njoroge et al. (2012) & $\begin{array}{l}\text { Modelo in vitro } \\
\text { Ensaio experi- } \\
\text { mental }\end{array}$ & $\begin{array}{l}\text { Cultura de células de } \\
\text { fibrose cística }\end{array}$ & $\begin{array}{l}\text { No } 6 \text { o dia, suplementação } \\
\text { com } 0,5,10 \text {, ou } 20 \mu \mathrm{M} \\
\text { de EPA e DHA }\end{array}$ & $\begin{array}{l}\text { DHA e EPA suprimiram a expressão } \\
\text { das enzimas 5- e 6-dessaturases e } \\
\downarrow \text { produção de AA }\end{array}$ \\
\hline Oliveira et al. (2010) & $\begin{array}{l}\text { Modelo humano } \\
\text { Ensaio clínico }\end{array}$ & $\begin{array}{l}17 \text { adultos } \\
\text { com FC } \\
\text { Um ano de inter- } \\
\text { venção }\end{array}$ & $\begin{array}{l}\text { Grupo intervenção (todos): } \\
324 \mathrm{mg} \text { de EPA, } 216 \text { mg de DHA, } \\
480 \mathrm{mg} \text { de } \mathrm{AL} \text { e } 258 \mathrm{mg} \text { de ácido gama- } \\
\text {-linoleico/dia }\end{array}$ & $\begin{array}{l}\text { Doses baixas de AG n-3 e AG } \\
\text { gama-linolênico pode melhorar } \\
\text { o estado pulmonar, inflamatório } \\
\text { e antropométrico }\end{array}$ \\
\hline Keen et al. (2010) & $\begin{array}{l}\text { Modelo humano } \\
\text { Ensaio clínico, } \\
\text { randomizado, } \\
\text { controlado } \\
\text { por placebo, } \\
\text { duplo-cego }\end{array}$ & $\begin{array}{l}43 \text { pacientes } \\
\text { com FC (mutações } \\
\text { graves) } \\
7 \text { a } 41 \text { anos de idade } \\
3 \text { meses de segui- } \\
\text { mento }\end{array}$ & $\begin{array}{l}3 \text { grupos }(A, B, C) \text { : misturas } \neq \text { de } 50 \mathrm{mg} / \\
\text { kg de } A G / \text { dia } \\
\text { Predominância de ômega } 3(A) \text { ou ôme- } \\
\text { ga } 6 \text { (B) ou AG saturado }(C) \text { (placebo) }\end{array}$ & $\begin{array}{l}\text { n-3 e n- } 6 \text { melhorou estado infla- } \\
\text { matório } \\
\text { ON nasal e exalado é influenciado } \\
\text { por aumento na [AA] }\end{array}$ \\
\hline Njoroge et al. (2015) & $\begin{array}{l}\text { Modelo animal } \\
\text { Ensaio experi- } \\
\text { mental }\end{array}$ & $\begin{array}{l}\text { Camundongos e } \\
\text { ratos com FC } \\
23 \text { dias de idade } \\
14 \text { dias de experi- } \\
\text { mento }\end{array}$ & $\begin{array}{l}\text { Dieta 1: Peptamen } \\
\text { Dieta 2: Peptamen por } 7 \text { dias }+40 \mathrm{mg} \\
\text { de DHA demais } 7 \text { dias } \\
\text { Dieta 3: Peptamen fórmula avançada } \\
\text { (fibra solúvel e óleo } \\
\text { de peixe refinado } 2,4 \mathrm{~g} / \mathrm{L} \text { de DHA e EPA) }\end{array}$ & $\begin{array}{l}\uparrow \uparrow \text { doses de DHA ou uma baixa } \\
\text { dose de DHA + EPA corrigiu as } \\
\text { anormalidades de AG e } \downarrow \text { dessatu- } \\
\text { rases e genes de elongase no íleo } \\
\text { e fígado } \\
\text { O DHA de } \uparrow \uparrow \text { dose } \downarrow \text { doença } \\
\text { nos tecidos, } \downarrow \text { acúmulo de muco } \\
\text { na sessão ileal }\end{array}$ \\
\hline $\begin{array}{l}\text { Alicandro et al. } \\
\text { (2013) }\end{array}$ & $\begin{array}{l}\text { Modelo humano } \\
\text { Ensaio clínico, } \\
\text { duplo-cego, } \\
\text { controlado por } \\
\text { placebo }\end{array}$ & $\begin{array}{l}41 \text { crianças: } 6 \text { a } 10 \\
\text { anos de idade } \\
1 \text { ano de seguimento }\end{array}$ & $\begin{array}{l}\text { Grupo intervenção: } \\
100 \mathrm{mg} / \mathrm{kg} / \text { dia } \mathrm{DHA} \text { durante o } 1 \text { o mês e } \\
\text { 1g/dia nos demais } 11 \text { meses } \\
\text { Grupo controle: } \\
\text { cápsulas com } 600 \mathrm{mg} \\
\text { de óleo de gérmen }\end{array}$ & $\begin{array}{l}\text { } \uparrow \text { plasmático DHA em paralelo } \\
\text { com uma diminuição em AA:DHA, } \\
\text { sugerindo melhor perfil inflama- } \\
\text { tório. }\end{array}$ \\
\hline Zaman et al. (2010) & $\begin{array}{l}\text { Modelo in vitro } \\
\text { Modelo in vivo } \\
\text { Ensaio experi- } \\
\text { mental }\end{array}$ & $\begin{array}{l}\text { Células com e sem FC } \\
\text { Ratos com e sem FC } \\
7 \text { dias de experimen- } \\
\text { to (células) } \\
10 \text { dias de experi- } \\
\text { mento (ratos) }\end{array}$ & $\begin{array}{l}\text { Células sense: com e sem AL } \\
\text { Células antisense: com e sem AL } \\
\text { Grupo ratos intervenção: } 100 \mathrm{mg} / \text { dia } \\
\text { de } \mathrm{AL} \\
\text { Grupo ratos controle: } 100 \mathrm{mg} / \text { dia de } \\
\text { ácido oleico } \\
\text { Ambos em Peptamen }\end{array}$ & $\begin{array}{l}\text { O AL } \uparrow A A, \text { IL-8 e eicosanoides em } \\
\text { células com FC. } \\
\text { O AL } \downarrow \text { função do RTFC e } \uparrow \text { níveis } \\
\text { AA e mediadores pró-inflamatórios } \\
\text { em ratos. } \\
\text { A suplementação AL pode incitar } \\
\text { e/ou propagar inflamação e ter } \\
\text { consequências clínicas prejudiciais } \\
\text { na FC }\end{array}$ \\
\hline
\end{tabular}

Fonte: Elaboração das autoras a partir dos estudos indicados.

Notas: $\mathrm{AG}=$ ácidos graxos; $\mathrm{DHA}=$ decosahexaenoico; $\mathrm{EPA}=$ eicosapentaenoico; $\mathrm{AL}=$ ácido linoleico; $\mathrm{FC}=$ Fibrose cística; RTFC = Regulador transmembrana da fibrose cística; $\mathrm{AA}=$ Ácido araquidônico; ON = Óxido nítrico; IL-8 = Interleucina 8; n-3 = ômega 3; n-6 = ômega 6 .

\section{DISCUSSÃO}

\section{Epidemiologia da fibrose cística}

A incidência da FC é de 1:2.500 nascidos vivos de etnia branca, com uma estimativa média de vida de 37 anos nos países desenvolvidos, nos quais cerca de um em cada 25 indivíduos é portador do gene heterozigótico ${ }^{13}$. Atualmente, são conhecidas cerca de 1.800 mutações $^{14}$, distribuídas nas classes I, II, III, IV e V, considerando-se do nível mais brando ao mais grave da doença, respectivamente $e^{1,3,13}$. Segundo Raskin. ${ }^{15}$, existiam no mundo, em 2003, aproximadamente 70.000 casos da doença e, nos Estados Unidos, cerca de 30.000 crianças e adultos possuíam diagnóstico de FC.

No Brasil, a incidência estimada de pacientes fibrocísticos é de 1 em cada 7.358 nascidos vivos, mas, em estudo realizado em cinco estados brasileiros (RS, SC, $P R, S P$ e MG), verificou-se uma incidência entre 1:1.587 e 1:32.258 nascidos vivos ${ }^{15}$. Por outro lado, dados da World Health Organization (WHO) ${ }^{32}$ revelam que, em 2009, a incidência de FC no Brasil foi de 1:6.902 nascidos vivos, sendo $47,7 \%$ dos portadores do gene F508del represen- 
tados por pacientes fibrocísticos. Quanto à prevalência, segundo o Grupo Brasileiro de Estudos de Fibrose Cística (GBEFC), 2.669 casos estão registrados no banco de dados da entidade ${ }^{17}$.

\section{Metabolismo lipídico na fibrose cística}

Os lipídios são classificados em triglicerídeos, colesterol, AG saturados (AGS) e AG insaturados (AGI). Dentre os AGIs, os AGEs, assim denominados por não poderem ser sintetizados pelo organismo humano ${ }^{18}$, são classificados como ácidos graxos monoinsaturados (MUFAs) e ácidos graxos poli-insaturados (PUFAs). Os MUFAs são da classe ômega 9 (oleico), e os PUFAs, da classe ômega 6 (linoleico) e ômega 3 (linolênico). Segundo a literatura científica, já está comprovado que o seu equilíbrio diminui a incidência de doenças cardiovasculares e complicações crônicas ${ }^{18,19}$.

A gordura atua como fonte de energia, contribuindo para a manutenção da temperatura corporal, servindo de base para hormônios e para a formação da membrana celular $^{20}$. Os AGEs, especialmente os PUFAs, são vitais para manter a integridade dessa membrana, visto que, em conjunto, modulam a resposta inflamatória, além de regular a produção hormonal e manter processos fisiológicos homeostáticos ${ }^{12}$. A partir do ácido linolênico, o organismo consegue sintetizar os dois mais importantes ácidos da classe $n-3$, o ácido eicosapentaenoico (EPA) e o ácido decosaexaenoico (DHA), que fornecem ao organismo importantes fatores anti-inflamatórios ${ }^{9,19,20}$. A maior cadeia longa de ômega 6 é o ácido araquidônico (AA), comumente associado ao aumento de eicosanoides pró-inflamatórios e do ácido Mead ${ }^{9}, 21,22,33$. A deficiência de PUFAs na FC é maior para AL e DHA; por outro lado, o AA apresenta concentração adequada ou até mesmo elevada. Acredita-se que, na deficiência de AL, pode existir a maior atuação da enzima dessaturase, ou seja, maior conversão de AL em AA a depender do gene da doença ${ }^{3}$.

Têm sido apontados os seguintes mecanismos para justificar a depleção de PUFAs em pacientes fibrocísticos: a má digestão, a má absorção de lipídios na dieta e o balanço energético negativo ${ }^{3}$. Entretanto, apesar de pesquisas atuais demonstrarem alterações em relação ao metabolismo lipídico nesses pacientes, essas evidências ainda não são conclusivas ${ }^{1,2,4,7,10,11,21,23}$.

Existem hipóteses sugestivas de que a má absorção de gorduras seja decorrente de uma mutação do gene da FC e não apenas da mucoviscidose ${ }^{1,4,6,7,9,10,11}$. Atualmente, vêm sendo levantadas algumas hipóteses para justificar essa alteração na FC: 0 aumento da atividade das enzimas delta- 5 e delta- 6 dessaturases ${ }^{10,22,24}$, a conversão facilitada de AA em eicosanoides $s^{4,10}$, podendo alguns pacientes apresentar, ainda, baixos níveis ou níveis dentro da faixa de normalidade de $\mathrm{AA}^{3}$.

Vale destacar que a disfunção causada pelo gene DF508CFTR, também conhecido como F508del em razão da ausência de fenilalanina na posição 508 e classificado como uma mutação de classe II, é a mutação mais comum, presente em $70 \%$ dos pacientes com $\mathrm{FC}^{1,23,24,25,34}$.
Essa mutação provoca uma mudança no metabolismo de lipídeos eicosanoides, promovendo o desequilíbrio entre os $n-3$ e $n-6$, tendo como resultado o aumento da produção de $A A^{1,23}$.

O AA é um precursor de metabólitos bioativos oxigenados conhecidos como eicosanoides, compostos que incluem as prostaglandinas e os leucotrienos, e o paciente fibrocístico possui uma elevada produção dessas substâncias pró-inflamatórias. Existe uma possível conexão entre AA e as manifestações fenotípicas da FC que estabelecem uma conexão entre as alterações dos eicosanoides e a patogênese da doença $a^{10,21}$.

\section{Efeitos dos ácidos graxos ômega 3 e ômega 6 na fibrose cística}

A normalização de perfil de AGE, especialmente da classe $n-3$, poderia corrigir o desequilíbrio desses AGs nas membranas celulares e diminuir os níveis sanguíneos de triglicerídeos, mediadores inflamatórios (TNF- $\alpha$ e IL-1) e imunoglobulina $\mathrm{G}(\operatorname{IgG})$, além de reduzir a razão entre leucotrienos das séries 4 e 5 (LTB4/LTB5). A ingestão de DHA pode amenizar a inflamação crônica na FC ao controlar a produção dos eicosanoides derivados do $A A^{4,5,6,7,10,11}$.

Em estudo de Oliveira et al. ${ }^{6}$ (Tabela 1), foi registrada uma melhora nos parâmetros respiratórios, nutricionais e nos marcadores de inflamação e oxidação, com a suplementação de uma combinação de baixas doses de AG n-3 e n-6 durante 12 meses. Além disso, foi possível normalizar o padrão da composição de AG de fosfolipídios séricos e melhorar os parâmetros clínicos (redução de exacerbações e cursos de antibióticos) e marcadores oxidativos. Esse estudo levanta a hipótese de que o perfil atípico de PUFAs poderia ser decorrente da mutação do gene DF508 do RTFC 1,6.

Biervliet et al. ${ }^{7}$ (Tabela 1) observaram um aumento significativo da concentração de DHA e EPA no grupo de intervenção, mesmo que esse último ácido não tenha sido suplementado, o que teria ocorrido em consequência da retroconversão de DHA em EPA, tendo a suplementação de DHA, permitido a redução de $A A$ na concentração em fosfolipídios. $O$ desequilíbrio entre a razão de AA e DHA contribui com as características inflamatórias nos pacientes fibrocísticos ${ }^{10,11}$. Supõe-se que uma mudança nessa razão pode induzir uma diminuição na inflamação e, secundária a ela, uma melhora da função pulmonar. Entretanto, não se obteve melhora clínica significativa e nenhuma mudança na inflamação medida pelo eritrócito, taxa de sedimentação e $\operatorname{lgG}$, o que pode ter acontecido pela dificuldade de avaliações clínicas em estudos com pequenas populações ${ }^{7}$.

Nos pacientes fibrocísticos, como acima referido, existe uma baixa concentração de AL, de DHA e, em contrapartida, pode existir uma alta concentração de $A A^{4,7,10,11,21}$. O AA, por sua vez, produz compostos eicosaenoides, por meio das enzimas cicloxigenase e 5-lipoxigenase ${ }^{12}$, além do aumento simultâneo das concentrações de ácido de Mead (20:3n-9) e de DPA (22:5n-6), os 
quais são marcadores de deficiência de AGE e mediadores inflamatórios ${ }^{4,7,10,21}$. Existem evidências de que as alterações no metabolismo de AG ocorrem não pela má absorção de lipídeos, mas pela conversão facilitada de AA em eicosanoides e pela expressão alterada das enzimas dessaturases ${ }^{4,10,21}$. Por outro lado, mediadores lipídicos derivados de n-3 PUFA, tais como o EPA e o DHA, podem diminuir a resposta inflamatória ${ }^{4}$.

Alicandro et al. ${ }^{4}$ (Tabela 1) constataram que a suplementação de DHA induziu um aumento de DHA sérico médio de $5 \%$ do AG total e uma diminuição paralela da razão AA:DHA. Essa diminuição sugere um efeito de inibição do DHA sobre as enzimas de dessaturação e elongases participantes da via metabólica de AG n-6. Além disso, o DHA também pode substituir o AA em pools de fosfolipídios, desde que ocorra a competição entre os dois principais PUFAs de cadeia longa (AA e DHA), na dependência da sua disponibilidade relativa ${ }^{4,7}$.

Njoroge et al. ${ }^{10}$ (Tabela 1) observaram o aumento da liberação de AA, que, por sua vez, aumentou o metabolismo de eicosanoides e elevou o metabolismo de fosfolipídios e o fluxo no interior das vias metabólicas de PUFAs $^{10,25}$. Estudos sugerem que essas alterações metabólicas se devem ao aumento da expressão e atividade de delta- 5 e de delta- 6 dessaturases de $A G^{4,10,11,24}$. Esse estudo demonstra que DHA diminuiu a expressão de delta- 5 e de delta- 6 dessaturases, levando a uma redução da conversão de AL em AA pela via metabólica $n-6$, invertendo, assim, as anormalidades dos PUFAs e o perfil inflamatório ${ }^{10}$.

Segundo Njoroge et al. ${ }^{11}$ (Tabela 1), a suplementação com doses elevadas ou mais baixas de DHA, associado, porém, com o EPA, reduziu a conversão de AL em AA em todos os tecidos examinados. Essa suplementação também foi eficaz na redução da expressão e da atividade enzimática das dessaturases. Esses achados são sugestivos de que ambas as formas de fornecimento de energia foram eficazes para reduzir a conversã $0^{11}$. Observou-se, também, uma significativa redução da produção de muco nas criptas do íleo, sendo essas mudanças possivelmente responsáveis pelas diferenças de expressão gênica no pulmão ${ }^{21}$.

Esses achados sugerem que a anormalidade histológica é corrigida com uma dose elevada de DHA ou com uma dose mais baixa de DHA associado ao EPA, tendo ocorrido essa alteração mesmo com as anormalidades dos PUFAs $\mathrm{n}-6$ corrigidas por ambas as dietas. Isso pode indicar que os fatores patológicos que contribuem para anormalidades histológicas, como hipersecreção ou diminuição da motilidade, estão mais associados com a deficiência de DHA do que com o excesso de produção de AA. Por fim, podem existir também mudanças em outras vias de $A G$ como a do ômega 7 e do ômega 9, evidenciando que a alteração no metabolismo lipídico e sua implicação ainda não é consenso ${ }^{11,21}$.

A fim de analisar a suplementação de AL, uma vez que seus níveis são reduzidos em pacientes fibrocísticos,
Zanam et al. ${ }^{12}$ (Tabela 1) realizaram um estudo experimental e demostraram que a suplementação de AL tem como resultado uma resposta inflamatória patológica in vitro e in vivo, e que a suplementação isolada com AL pode incitar e/ou propagar a inflamação com consequências clínicas prejudiciais ${ }^{12}$.

Outros sim, o prejuízo pulmonar é responsável pelo maior índice de mortalidade em pacientes com $\mathrm{FC}$, comprometimento que ocorre por uma série de inflamações e infeç̧ões de repetição que estimulam no organismo uma resposta anti-inflamatória exagerada. Os portadores de FC estão sujeitos a um aumento significativo de inflamação das vias aéreas, com elevação de neutrófilos ativados e citocinas pró-inflamatórias, e a uma diminuição de citocinas anti-inflamatórias. Assim sendo, o tratamento da obstrução das vias aéreas e das infecções respiratórias, o controle da inflamação e o suporte nutricional adequado são fatores-chave para retardar danos aos pulmões ${ }^{6,12}$.

A colonização bacteriana das vias aéreas com Staphylococcus aureus pode promover a colonização crônica por Pseudomonas aeruginosa, gerando respostas inflamatórias persistentes que causam danos ao tecido, sendo uma das manifestações clínicas mais importantes na $\mathrm{FC}^{6,9}$. Segundo Keen et al. ${ }^{9}$ (Tabela 1), o óxido nítrico (ON) tem mostrado importantes propriedades antimicrobianas na mucosa nasal e na secreção nasal. Em pacientes fibrocísticos, a quantidade de ON nasal é normal ou baixa e, na secreção, é diminuída. Uma explicação para a baixa concentração de ON exalado são altas taxas de AA, ácido que, como se sabe, é um inibidor da síntese de ON. Desse modo, é possível levantar-se a hipótese de que anormalidades do metabolismo lipídico sejam responsáveis pela baixa concentração de $\mathrm{ON}$ em indivíduos com $\mathrm{FC}$ e, consequentemente, pela menor capacidade de defesa contra infecções respiratórias e pulmonares $\mathrm{s}^{6,9}$.

O estudo de Keen et al. ${ }^{9}$ demonstra que a suplementação, de curto prazo, de lipídios da classe $\mathrm{n}-3$ dietéticos influencia no padrão de fosfolipídios séricos, de AG e de marcadores imunológicos em pacientes fibrocísticos clinicamente estáveis. Não houve alteração no ON nasal e exalado com a suplementação de $n-3$, mas constatou-se aumento significativo das concentrações séricas de $n-3$, bem como redução de níveis da taxa de sedimentação de eritrócitos (ESR) e de interleucina 8 (IL-8), indicativa de uma menor inflamação ${ }^{9}$. Discute-se se o suplemento com EPA e DHA teria resultado em uma inibição da inflamação e, consequentemente, em redução no ON nasal; nesse caso, o aumento de ON pela suplementação não seria significativo, e isso explicaria por que ON nasal não se alterou após a suplementação de n-3. Outra hipótese seria um maior impacto da concentração de AA sobre a produção de $\mathrm{ON}^{9}$. Ressalte-se que, em pacientes com $\mathrm{FC}$, o AA é frequentemente aumentado na mucosa nasal e em secreções brônquicas, o que seria uma justificativa para o baixo teor de ON nas vias aéreas ${ }^{6,9}$. 


\section{Efeitos colaterais da suplementação de PUFAs na fibrose cística}

Em outro estudo realizado por Keen et al. ${ }^{9}$, houve poucos efeitos colaterais advindos da suplementação de PUFAs, com exceção de ganho de peso. Entretanto, alguns pacientes se queixaram de dor abdominal inespecífica, que é um sintoma comum na FC, não devendo, portanto, atribuir-se ao tratamento.

No estudo de Oliveira et al. ${ }^{6}$ não foram relatados efeitos colaterais significativos tais como diarreia, esteatorreia ou que gerassem a necessidade de aumentar as doses de enzimas pancreáticas. No entanto, dois pacientes selecionados para o estudo abandonaram o tratamento na primeira semana sob a alegação de intolerância digestiva (arrotos e regurgitação com gosto de peixe), efeitos esses que poderiam ter sido minimizados pela administração de outro fármaco.

Tabela 2 - Recomendações para a razão entre ômega 6 e ômega 3 na dieta, segundo entidades internacionais

\begin{tabular}{lll}
\hline País ou Instituição & $\mathbf{n}-\mathbf{6 / n} \mathbf{n} \mathbf{3}$ & Referências \\
\hline Canadá & $4: 1-10: 1$ & SCR $^{28}$ \\
EUA & $2: 1-4: 1$ & Simopoulos $^{29} ;$ Schaefer $^{30}$ \\
WHO/FAO & $5: 1-10: 1$ & WHO $^{31}$ \\
\hline
\end{tabular}

Fonte: Elaboração das autoras a partir dos estudos indicados.

Notas: $\mathrm{WHO}=$ World Health Organization; FAO $=$ Food and Agriculture Organization;

SRC = Scientific Review Committee.

Em associação à ingestão de gorduras poli-insaturadas, pacientes fibrocísticos necessitam, na maioria dos casos, da suplementação de enzimas pancreáticas, ainda que não tenham desenvolvido a IP, na tentativa de aumentar a absorção de gordura proveniente da dieta ${ }^{3,6,10,11,21,22,24}$.

CONCLUSÃO

Pequenas doses de PUFAs suplementadas aos pacientes fibrocísticos apresentaram efeito benéfico e de normalização dos níveis séricos de AA, DHA, AL e EPA, diminuindo o quadro inflamatório crônico e propiciando melhoras histológicas e clínicas. Contudo, ainda não existe um consenso sobre o tempo e a quantidade de suplementação de PUFAs, e até que ponto essa administração pode ser considerada benéfica.

Diante do exposto, é possível concluir que muitos estudos ainda devem ser dedicados aos portadores de FC, mas a suplementação de PUFAs, em especial de $n-3$, pode ser uma alternativa interessante no manejo dessa doença.

\section{REFERÊNCIAS}

1. GELFOND, D.; BOROWITZ, D. Gastrointestinal complications of cystic fibrosis. Clin. Gastroenterol. Hepatol., Philadelphia, v. 11, n. 4, p. 333342, Apr. 2013.

2. RISÉ, P. et al. Whole blood fatty acid analysis with micromethod in cystic fibrosis and pulmonary disease. J. Cyst. Fibros., Amsterdam, v. 9, n. 3, p. 228-233, May 2010.

3. SINAASAPPEL, M. et al. Nutrition in patients with cystic fibrosis: a Euro-

\section{Recomendações de ácidos graxos poli-insaturados}

Ainda não existe um consenso para a dosagem ideal de suplementação de AGE, bem como para o tipo de AGE a ser administrado em pacientes com FC. Apesar da indicação de uma dose padrão de DHA 1,0-1,02g/dia, que é suficiente para aumentar o DHA sérico de 4-5\% mol,7,15, fazem-se necessários mais experimentos em relação a essa dosagem ${ }^{26,6}$. Existem relatos de que, na Suécia, pacientes com $\mathrm{FC}$ recebem, geralmente, a orientação de consumir, por dia, 1-2 colheres de sopa de gordura extra, rica em AGE, como óleo de girassol ou óleo de milho. Essa poderia ser uma das explicações para os pacientes com FC dessa população terem boas condições clínicas na vida adulta ${ }^{9,27}$. Não existe, igualmente, um consenso em relação à razão de $n-6: n 3$, mas algumas instituições internacionais disponibilizam as recomendações aqui reunidas na Tabela 2.

pean consensus. J. Cyst. Fibros., Amsterdam, v.1, n.2, p.51-75, June 2002.

4. ALICANDRO, G. et al. A randomized placebo-controlled study on highdose oral algal docosahexaenoic acid supplementation in children with cystic fibrosis. Prostaglandins Leukot. Essent. Fatty Acids, Edinburgh, v.88, n.2, p.163-169, Feb. 2013.

5. CHAVES, C. R. M. M.; CUNHA, A. L. P. Avaliação e recomendações nutricionais para crianças e adolescentes com fibrose cística. Rev. Paul. Pediatr, São Paulo, v. 30, n. 1, p.131-138, 2012.

6. OLIVEIRA, G. et al. Fatty acid supplementation improves respiratory, inflammatory and nutritional parameters in adults with cystic fibrosis. J. Cyst. Fibros., Amsterdam, v. 46, n.2, p.70-77, Feb. 2010.

7. BIERVLIET, S. V. et al. Oral DHA supplementation in DF508 homozygous cystic fibrosis patients. Prostaglandins Leukot. Essent. Fatty Acids, Edinburgh, v.78, n.2, p.109-115, Feb. 2008.

8. GIUDETTIA, A. M.; CAGNAZZO, R. Beneficial effects of $n-3$ PUFA on chronic airway inflammatory diseases. Prostaglandins and Other Lipid. Mediat., New York, v. 99, n.3/4, p.57-67, Dec. 2012.

9. KEEN, C. et al. Supplementation with fatty acids influences the airway nitric oxide and inflammatory markers in patients with cystic fibrosis. J. Pediatr. Gastroenterol. Nutr., New York, v. 50, n. 5, p.537-544, May. 2010.

10. NJOROGE, S. W. et al. DHA and EPA reverse cystic fibrosis-related FA abnormalities by suppressing FA desaturase expression and activity. J. Lipid Res., Bethesda, v. 53, n.2, p.257-265, Feb. 2012.

11. NJOROGE, S. W. et al. Polyunsaturated fatty acid supplementation reverses cystic fibrosis-related fatty acid abnormalities in CFTR-/- mice by suppressing fatty acid desaturases. J. Nutr. Biochem., Stoneham, v. 26, n. 1, p. 36-43, Jan. 2015.

12. ZAMAN, M. M. et al. Linoleic acid supplementation results in increased arachidonic acid and eicosanoid production in CF airway cells and in cftr-/-transgenic mice. Am. J. Physiol. Lung Cell Mol. Physiol., Bethesda, v. 299, n. 5, p. 599-606, Nov. 2010.

13. ASSOCIAÇÃO MÉDICA BRASILEIRA; ASSOCIAÇÃO NACIONAL DE SAÚDE SUPLEMENTAR. Diretrizes Clínicas na Saúde Complementar. Fibrose

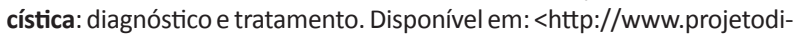
retrizes.org.br/ans/diretrizes/fibrose_cistica-diagnostico_e_tratamento. pdf >. Acesso em: 29 mar. 2015.

14. CISTIC FIBROSIS FOUNDATION. Clinical and Functional Translation 
of CFTR (CFTR2). 2015. Disponível em: <http://www.cftr2.org/index. php >. Acesso em: 30 mar. 2015.

15. RASKIN, S. Estudo multicêntrico das bases da genética molecular e da epidemiologia da fibrose cística em populações brasileiras. 2001. Tese (Doutorado) - Universidade Federal do Paraná, Curitiba, 2001.

16. FIRMIDA, M. de C.; LOPES, A. J. Aspectos Epidemiológicos da Fibrose Cística. Hospital Universitário Pedro Ernesto (UERJ), Rio de Janeiro, v. 10, n. 4, p. 12-22, out/dez. 2011.

17. GRUPO BRASILEIRO DE ESTUDOS DE FIBROSE CÍSTICA. Registro Brasileiro de Fibrose Cística: Relatório 2012. p.5. Disponível em: <http:// www.gbefc.org.br/>. Acesso em: 17 maio 2015.

18. COZZOLINO, S. M. F. Biodisponibilidade de nutrientes. 4. ed. São Paulo: Manole, 2012. 1334 p.

19. NELSON, D. L.; COX, M. M. Princípios de bioquímica de Lehninger. 5. ed. Porto Alegre: ARTMED, 2011. p. 1304.

20. VIJ, N. Linoleic acid supplement in cystic fibrosis: friend or foe? Am. J. Physiol. Lung Cell Mol. Physiol., Bethesda, v. 299, n. 5, p. L597-L598, Nov. 2010.

21. SEEGMILLER, A. C. Abnormal unsaturated fatty acid metabolism in cystic fibrosis: biochemical mechanisms and clinical implications. Int. J. Mol. Sci., Basel, v. 15, n. 9, p.16083-16099, Sept. 2014.

22. WITTERS, P. et al. Lung transplantation in cystic fibrosis normalizes essential fatty acid profiles. J. Cyst. Fibros., Amsterdam, v. 12, n. 3, p. 222-228, May. 2013.

23. WORGALL, T. S. Lipid metabolism in cystic fibrosis. Curr. Opin. Clin. Nutr. Metab. Care, London, v. 12, n. 2, p. 105-109, Mar. 2009.

24. NJOROGE, S. W. et al. Increased $\Delta 5$ - and $\Delta 6$-desaturase, cyclooxygenase-2, and lipoxygenase- 5 expression and activity are associated with fatty acid and eicosanoid changes in cystic fibrosis. Biochim. Biophys. Acta, Amsterdam, v. 1811, n. 7/8, p. 431-440, July/Aug. 2011.

25. O'SULLIVAN, B. P.; FREEDMAN, S. D. Cystic fibrosis. Lancet, London, v. 373, n. 9678, p. 1891-1904, May 2009.

26. MAQBOOL, A. et al. Relation between dietary fat intake type and serum fatty acid status in children with cystic fibrosis. J. Pediatr. Gastroenterol. Nutr., New York, v. 55, n. 5, p. 605-611, Nov. 2012.

27. STRANDVIK, B. Nutritional management of cystic fibrosis. Ann. Nestle Eng., Basel, v. 49, n. 1, p.38-46, 1991.

28. SCIENTIFIC REVIEW COMMITTEE. Nutrition recommendations. Ottawa: Canadian Government Publishing Centre, Supply and Services Canada, 1990.

29. SIMOPOULOS, A. P.; LEAF, A.; JÚNIOR SALEM, N. Essentiality and recommended dietary intakes for omega- 6 and omega-3 fatty acids. Ann. Nutr. Metab., Basel, v. 43, n. 2, p.127-130, 1999.

30. SCHAEFER, E. J. Lipoproteins, nutrition, and heart disease. Am. J. Clin. Nutr., Bethesda, v. 75, n. 2, p. 191-212, Feb. 2002.

31. WHO and FAO Joint consultation: fats and oils in human nutrition. Nutr. Rev., New York, v. 53, n. 7, 205 p., July 1995.

32.WORLD HEALTH ORGANIZATION. The molecular genetic epidemiology of cystic fibrosis. Geneve, p. 2002.

33. ICHI, I. et al. Identification of genes and pathways involved in the synthesis of Mead acid (20:3n-9), an indicator of essential fatty acid deficiency. Biochim. Biophys. Acta, Amsterdam, v. 1841, n. 1, p. 204213, Jan. 2014.

34. ALDAMIZ-ECHEVARRÍA, L. et al. Persistence of Essential Fatty Acid Deficiency in Cystic Fibrosis Despite Nutritional Therapy. Pediatr. Res., Reino Unido, v. 66, n. 5, p 585-589, 2009.

Submetido em: 23/08/2015

Aceito em: 09/12/2015 